of the post-mortem examination, the pericardium contained the contents of a large hepatic abscess.

Sectio cadaveris. - In consequence of a desire to make a morbid preparation for our Pathological Museum at Colombo, the several organs were not disturbed more than was necessary by Mr. Markus, assistant-surgeon of the hospital, who conducted the post-mortem examination. The body was much swollen. on opening the middle mediastinum, the pericardium was found distended with a large quantity of purulent matter. On examination, an opening was clearly observed leading from the pericardium downwards and to the right side into the substance of the liver. Lungs slightly congested posteriorly. The cavity of the pleura contained a large quantity of serous fluid. The abdominal cavity contained several pints of straw.coloured serum. Liver very much enlarged; a large abscess on its convex surface, which opened into the pericardium. Other organs healthy. The heart, liver, and lungs were placed in spirits and despatched to Colombo.

Remarks. - A belief is very generally entertained that hepatic abscess, the result of acute inflammation, is " exceedingly rare" amongst Asiatics, and that it is a disease peculiar to the Europeans in India. It was Twining, I believe. who first suggested the idea; but the particulars of the above case, the records of our large Native Hospital, and the experience of such men as Morehead, negative the idea. Indeed, the results of the Bombay Native Hospital show that the rate of mortality has been considerably higher from hepatic disease in natives than in the European General Hospital of that presidency. And Dr. Jackson, in the paper from which I have quoted, recolds it as his conviction that superficial abscesses pointing towards the abdomen are not uncommon amongst the natives of India.

Our observation, so far as it has gone, has convinced me that "liver abscess" is not an "exceedingly rare" disease amongst Asiatics; and we moreover find in the writings of Staff-Surgeon Marshall, who served in Ceylon many years ago, that abscesses of the liver both in the native arwy and amongst Africans were not uncommon.

On the other hand, we are not convinced that acute hepatitis is an every-day disease with the European, or that "the Ziver" is a disease exclusively of the Europeans in India. We sincerely believe that this organ is more frequently sinned against than sinning. As every case of dysentery some years ago was thought to be connected with liver affection, so we fear that in many cases of abdominal derangement, particularly of the small intestines, the liver came in for a large share of blue-pill.*

But whilst hepatic abscess in the European in India is confessedly a very fatal disease, in the native it is a much more obscure one, rendering the formation of a correct diagnosis a very difficult matter, when, as in the case just detailed, the abscess does not show a tendency towards the abdominal parietes. The group of symptoms indicative of abscess is far less appreciable in them than in the European. Not uufrequently, in the conduct of post-mortem examinations, we come upon small abscesses of the liver, which were not indicated during life-time by any symptom; and this is not to be wondered at, when, even in the European, the presence of a limited abscess has been found by observant physicians to be not incongistent with the existence and enjoyment of tolerable health. +

The case which I have reported presented none of those symptoms which are generally relied on as indications of hepatic abscess. There were no rigors, + no marked acceleration of the pulse, no tension of the right rectus, no bulging of the right side, nor pain in the right shoulder; and even the test so much relied upon by Annesley and the older Indian writersmercury not producing salivation-failed here. The patient readily came under the influence of blue pill.

The extreme difficulty, nay the impossibility, of bringing a patient with abscess of the liver under the influence of mercury is so much relied on by Dr. Jackson, that he looks upon ptyalism as the experimentum crucis.

But this is the second failure of the test within a short time.

* It must be acknowledged that functional disorders of the liver are often assumed to exist on very vague and trivial grounds, and modes of treatment adopted in exist on very vague and trivial grounds, and modes of treatment often unnecessary, and it is to be feared sometimes absolutely injurious.Twrining on "Diseases of is to be

$\uparrow$ Budd on the Liver, page 82

I In two cases of hepatitis amongst Curopean planters, rigors were present I In two cases of hepatitis amongst curopean planters, rigors were present
erery day for a week and ten days, bnt they were not conclusive of abscess. In a gentleman who had suffered more than once from liver abscess, after leeching and blistering, rigors set in, and caused some anxiety, but they were not indicative of suppuration. My friend, MIr. Loos, in charge of the European Seamen's Hospital at Colombo, very lately operated in a case of liver abscess, in vhich rigors were altogether absent.
The other case was that of a European clerk, in the employ of a merchant in Kandy. He was salivated by a few doses of blue-pill, given for an attack of dysentery, which supervened on "liver." Abscess was clearly diagnosed shortly afterwards, of which he died after operation.

Ceylon, 1861.

REPORT OF A

\section{CASE OF POISONING WITH BICHLORIDE} OF MERCURY.

\section{By JOHN J. SKEGG, L.R.C.P. EDIr., \&o.}

The following case of poisoning with corrosive sublimate may not be uninteresting to the profession, showing the rapidity of its fatal effect, the patient dying in three hours and a quarter after swallowing the suicidal dose.

In Dr. Taylor's aajmirable work on Medical Jurisprudence, a case is reported by Mr. Welch in which a man died in less than half an hour: the quantity of the poison was not ascertained. In the same book is mentioned another case, that of a child who was killed in three hours after taking eighteen grains. In acute cases, death usually occurs in from one to five days. In my case the dose was a very large one-a quarter of an ounce; and its being in a state of solution of course added very much to the quickness of the fatal termination.

On the 27th September, 1861, at eleven in the morning, I was hastily summoned to $R$. S- an army accoutrement maker, who, I was informed, had just taken poison. Upon my arrival, I found him to be a strong muscular man of about fifty-four years of age. He lay in a state of great prostration on the bed (the skin blanched, and covered with a cold clammy perspiration), vomiting a thick, stringy, albuminons-looking substance; great purging, partly blood; intense pain over the abdomen; the tongue and interior of the mouth perfectly white from the contact of the poison; pulse scarcely perceptible.

Upon making inquiries of him, he told me that he had swal. lowed twopennyworth of corrosive sublimate; also informed me where he had purchased it, and that he had kept it in his pocket the last week in a state of solution, contemplating suicide. I afterwards learnt at the shop that a quarter of an ounce was sold for that sum.

I immediately administered the white of erg, at the same time encouraging vomiting; milk was given ad libitum, and at intervals brandy-and-water; a mustard poultice over the whole of the abdomen. I remained with him for one hour.

At one o'clock I saw him again. He appeared much in the same condition, but lower and more depressed. At a quarter past two I paid another visit, and found he had just expired.

Autopsy twenty-four hours after death. -Upon opening the abdomen, the exterior of the stomach was found to be of a deep-red colour; the interior had more the appearance of $a$ piece of dark-crimson velvet, owing to the large amount of extravasated blood. The intestines here and there were reddened. That portion of the omentum attached to the stomach was of a deep-crimson hue for one inch from the margin of that viscus. The other organs were in a healthy state. St. Martin's-place, Trafalgar-square, Jan. 1862.

UNIVERSITY OF HDINBURGH. - The sum of 40,000 rupees has been invested in Indian Securities by John Muir, of the Bengal Civil Service, D.C.L. of Oxford and LL.D. of Edinburuh, for the endowment of a chair of "Sanscrit Language, Li'erature, and Philosophy, and of Comparative Philology," in the University of Edinburgh. The endowment is granted on the conditions that the free proceeds of the sum, which is invested at 5 per cent., shall be annually paid to a professor to be appointed, and that the Treasury shall grant the additional sum of $£ 200$ per annum for the endowment of the chair; that the first appointment shall be made by $\mathrm{Dr}$. Muir, the patronage to be subsequently vested in the Crown; and that such fees shall be exacted from the students as the University Court may sanction. The munificent gift of Dr. Muir to the Universicy has been received with great satisfaction, there having been hitherto no provision for the teaching of Sanscrit there, excepting in connexion with the Hebrew chair. The large number of Edinburgh students who look forward to the Indian service renders the new chair a most im. portant acquisition to the University. 